\title{
FREE PARKING FOR ALL IN SHOPPING MALLS*
}

\author{
By KeVIN HASKER AND EREN INCI ${ }^{1}$
}

Bilkent University, Turkey; Sabanci University, Turkey

\begin{abstract}
We show why a mall provides parking for free and embed the parking costs in the prices of the goods. Essentially, charging a parking fee to risk-averse customers means penalizing them for not finding their desired good. This result holds whether the mall has monopoly power or prices competitively, if there is parking validation, and if there is a trade-off between shopping and parking spaces. It is also the attainable social optimum. The equilibrium lot size is too small, yielding a rationale for minimum parking requirements. However, parking fees may be positive and lots may be too large in urban malls.
\end{abstract}

\section{INTRODUCTION}

The average Joe does not think much about parking, but economists should. Other than money and credit cards, parking is probably the most important intermediate good in the modern economy. Needless to say, it consumes a vast quantity of natural resources. The total amount of land devoted to parking in the United States would cover several New England states (Jakle and Sculle, 2004, pp. 1-2). And the price put on this commodity is very low. The U.S. Department of Transportation (1990) found that parking was free for $99 \%$ of car trips. Shopping malls are one of the largest contributors to the stock of parking spaces. There are over 100,000 shopping malls in the United States. A typical shopping mall has four to six parking spaces per 1,000 square feet of gross leasable area, suggesting that the average mall has more space allocated to parking than stores (International Council of Shopping Centers and Urban Land Institute, 2003, henceforth ICSC and ULI, 2003). More interestingly, in the same survey, $94 \%$ of the malls reported that they charged no fee for parking and $4 \%$ did not respond to this question. Thus, we can only be sure that $2 \%$ of these parking spaces have any fee whatsoever. Shoup (2005) estimates the cost of a parking space in the United States to be at least $\$ 125$ a month. He then asks, "if parking costs so much, why is it usually free?"

Based on these figures, the literature finds parking too cheap and its quantity too high, especially given the negative externalities from congestion and air pollution. This research focuses mainly on urban areas where these externalities are most severe. There has also been increasing attention to minimum parking requirements that force property developers to allocate land for parking (van Ommeren and Wentink, 2012). Many towns and cities impose these requirements even though no one knows what they are based on (Shoup, 1999, 2005, 2006). Is underpricing an issue for all forms of parking? Are minimum parking requirements unnecessary or irrational, or are they justified for some land uses? Our article finds that parking is priced

\footnotetext{
*Manuscript received September 2012; revised June 2013.

${ }^{1}$ This article won the Best Paper Award at the Kuhmo Nectar Conference on Transport Economics 2010. The authors would like to thank Richard Arnott, Fulya Yuksel Ersoy, Inci Gumus, Firat Inceoglu, Jos van Ommeren, and Charles Horioka (the editor), the three anonymous referees, seminar participants at Bilkent University, Middle East Technical University, Sabanci University, TOBB Economics and Technology University, and the University of East Anglia, and session participants at 2011 North American Summer Meeting of the Econometric Society, the 11th Annual Conference of the Association for Public Economic Theory, and the Kuhmo Nectar Conference on Transport Economics 2010 for their valuable comments. Any remaining errors are the responsibility of the authors.

Please address correspondence to: Eren Inci, Faculty of Arts and Social Sciences, Sabanci University, Orhanli/Tuzla, 34956 Istanbul, Turkey (TR). Phone: +90-216-483-9340. Fax: +90-216-483-9250. E-mail: ereninci@sabanciuniv.edu.
} 
properly in shopping malls, that both society and the shopping mall want parking to be free, and furthermore that society generally wants to require minimum parking lot sizes.

Our contribution to the literature begins by noting that there are three parties in the parking problem, one of which previous research has not analyzed. These parties are the customer, the primary demander of parking; the parking lot, the supplier; and the store, which acts as a secondary demander for parking. Because stores rely on parking for business, they are vitally concerned with how much parking is available and its price. Most of the literature focuses on the customers and the negative externalities they impose on each other. Some papersnotably Arnott (2006) and Arnott and Rowse (2009)-focus on the incentives of the parking lot provider, but no paper incorporates stores into the scheme and combines all three parties.

This article is a first analysis of the shopping mall parking problem. What makes shopping mall parking a convenient problem to work with is that modeling the parking provider and the stores as one economic entity is harmless. ${ }^{2}$ This simplifies the analysis of the optimal price and quantity of parking. Shopping malls have two methods to charge customers for parking. They can raise either the price of the good or the parking fee. What we find is that both the shopping mall and society want the price of the good to absorb the entire cost of parking. Moreover, a social planner always wants the mall to provide more than the profit-maximizing amount of parking. This justifies the common implementation of minimum parking requirements. To our knowledge, ours is the first attempt to explain the foundations of minimum parking requirements. ${ }^{3}$

The key to our analysis is recognizing that sometimes shoppers do not find what they want. We do not argue that this is the normal outcome, merely that it occurs. For example, one of the authors is still searching for a footstool high enough for his son. The other author's wife went to seven different malls before buying a dress for a wedding. On a weekly basis, grocery shopping often includes searching for some goods that may not be there. These searches add a significant amount of time to a shopping trip, and if the parking fee is hourly one would have the marginal choice we discuss here. ${ }^{4}$

When purchase decision is uncertain, charging a parking fee to risk-averse customers is like charging them for losing a lottery. ${ }^{5}$ Thus, both the mall and society want the cost of parking embedded in the price of the goods. In fact, the mall would like to fully insure the marginal customer, who is indifferent between visiting and not visiting the mall, but this would require negative parking fees and is not implementable. Although this result requires risk aversion, the degree of risk aversion does not matter. Thus, it holds no matter how small the good is relative to the customer's wealth. It is also quite robust. It holds if the shopping mall has monopoly

\footnotetext{
${ }^{2}$ In reality, the mall generally does not own any of the stores in the mall and does not directly sell goods. However, the stores almost certainly have a strong input into the parking fee, and the mall has strong input into the price of goods. In fact, many rental leases in malls require tenants to pay a percentage of their gross income-effectively merging the two parties' interests (Wheaton, 2000).

${ }^{3}$ One motivation could be to prevent free riding on the parking space of neighboring properties, but the application of the rules is not contingent on the nearby parking spaces. Another motivation could be that on-street parking is not appropriately priced. Arnott (2006) discusses potential effects of minimum (and maximum) parking requirements, and van Ommeren and Wentink (2012) quantify the welfare loss caused by them, but they do not focus on explaining their rationale.

${ }^{4}$ Shopping malls are well aware of this risk. A statistic they collect and analyze is the conversion rate, which is the probability a customer buys conditional on him visiting a store. According to ICSC research reported by Connolly and Rogoff (2008), the average shopper visits 1 department store and 1.8 other stores per visit. The conversion rate for department stores is approximately 0.6 , and for other stores is approximately 0.5 . If we assume that there are three department stores and 50 other stores in a mall and the distribution of number of (department) stores visited is Poisson, the overall mall conversion rate is 0.78 . If the number of stores is varied between 1 and 100 and the number of department stores between 1 and 10, the conversion rate robustly stays within the band $0.77-0.83$ with the assumed Poisson distribution. Anecdotal evidence emphasizes the importance of this statistic. A colleague was pacing in and out of a store while his wife was shopping. A salesperson asked him to stop because he was lowering her measured conversion rate.

${ }^{5}$ The assumption of risk aversion is strongly supported in the economic literature. Holt and Laury (2002) show in an experiment that subjects are risk averse over small gambles. Barberis et al. (2006), Cohen and Einav (2007), and Harrison and Rutstrom (2008) find similar results. Moreover, risk-neutral customers with a binding time constraint behave as if they were risk averse (see Drewianka, 2008).
} 
power or prices competitively. It holds even if we allow the shopping mall to provide parking vouchers or if it faces a trade-off between the space devoted to shopping and to parking.

We derive these results in a model where a monopolist shopping mall sells one good to homogeneous customers. We treat the shopping mall as a monopolist because we want to avoid competitive explanations for free parking. A standard result is that prices decrease in the face of competition; thus, if we find that parking is free for a monopolist mall, then we expect that it will be free for a mall in a competitive environment. We verify this in a reduced-form competitive variation of our model. Furthermore, notice that the mall's goal is not to insure the customer. Like the principal-agent model with moral hazard, it simply finds that insuring the customer maximizes its profits. In addition, although we have homogeneous customers and one good in our model, we are not arguing that every customer faces this uncertainty. Rather, what is important for our argument is that the marginal customer does, or, if there are heterogeneous goods, then the customer faces this uncertainty with regard to some of the goods he would like to purchase.

ICSC and ULI (2003) reported that shopping malls that charge for parking are mostly located in large urban areas. In keeping with the survey findings, our results change when we look at an urban mall. We define a shopping mall as suburban if the only reason to use the parking lot of the mall is to shop at the mall; otherwise it is urban. In urban malls, parking is more like a commodity and thus should be priced independently, or the mall may behave like a parking garage. In maximizing profit, the urban mall has to balance providing insurance to shoppers with trying to extract surplus from nonshoppers. This results in positive parking fees if the latter motive dominates.

Another crucial difference in the urban mall is the land allocation trade-off that prevents the mall from expanding the parking lot without shrinking the size of the store space. In such environments, it is no longer clear that society wants a larger parking lot than the shopping mall. This may explain why some large cities and smaller towns in the United States, such as San Francisco, Seattle, San Antonio, Portland (Oregon), Cambridge (Massachusetts), Redmond (Washington), Queen Cree (Arizona), and Concord (North Carolina), have also begun regulating the maximum parking lot size. The United Kingdom also started imposing maximum parking requirements throughout the country, most likely because their land allocation trade-off is more intense.

A small but rapidly growing literature in economics deals with parking. One group of papers focuses on the price of parking, whereas a relatively smaller group looks at land use and parking requirements. To our knowledge, no paper in the literature analyzes the economics of shopping mall parking. The whole literature is shaped by Vickrey's (1954) idea of pricing parking at its social opportunity cost, just like any other commodity. Perhaps the most influential work in both parking pricing and land use is Shoup (2005), which underlines the high cost of free parking in all of its modes. Although it is undeniable that parking has high social costs, we argue that it may be better for society to reflect these costs in the price of goods.

Early theoretical work focuses on how congestion externalities influence parking fees. Glazer and Niskanen (1992) point out that hourly parking fees may increase congestion by causing shorter parking durations. Arnott et al. (1991) analyze the optimal temporal-spatial dispersion of parking fees and derive the prices that eliminate queuing and induce drivers to park at the most distant parking spaces first. Anderson and de Palma $(2004,2007)$ build on similar arguments in a linear-city model and find that the optimal price can be attained by monopolistically competitive pricing. Arnott and Rowse (1999) consider a circular city and find that the optimal fee is equal to the externality imposed, but the optimal parking fee may not work since traffic may end up in a bad equilibrium.

A recent surge of work elaborates on cruising for parking. Arnott and Inci (2006) find the optimal fees and quantity of on-street parking to eliminate cruising, and Arnott and Inci (2010) analyze the transient dynamics of downtown parking and traffic. Arnott et al. (2013) consider the optimal on-street parking capacity when there are competitive parking garages. Calthrop and Proost (2006) analyze the optimal parking fee when both on- and off-street parking are available. 
On the empirical side, van Ommeren et al. (2011) estimate the cost of cruising in Amsterdam, and using a nationwide dataset, van Ommeren et al. (2012) provide comprehensive descriptive information on cruising for parking and its determinants in the Netherlands.

Arbatskaya et al. (2007) provide another rationale for why parking lots in shopping malls are so large and why this may be socially desirable. The basic insight is that if the demand for parking is higher than supply by a small amount, then not only will some drivers be unable to find parking but all drivers will arrive early to be sure of finding a space. This results in a significant decrease in welfare. This is similar to Vickrey (1969), where drivers arrive early to the bottleneck to avoid the delay.

There is relatively little analysis of the optimal lot size for off-street parking. Arnott (2006) derives the capacity chosen by parking garages and considers the potential effects of minimum and maximum parking requirements. In practice, determining the minimal lot size is at best an ad hoc practice. Shoup $(1999,2005)$ rightfully criticizes minimum parking requirements because no one knows the criteria behind them or their justification. Shoup (1999) reports from Willson's (1996) survey of 144 planning directors: Two of the most frequently used methods in determining parking requirements are surveying nearby cities and consulting the handbooks of the Institute of Transportation Engineers. He concludes that minimum parking requirements distort land use and recommends eliminating them for all land uses. We show that they are well justified and could be structurally based for shopping malls.

The rest of this article is organized as follows: Section 2 presents the base model and derives the equilibrium and socially optimal parking fees followed by a discussion of parking validation and a competitive variation of the model. Section 3 modifies the base model to analyze the lot size. Section 4 discusses two urban complications: the possibility of free riding on parking spaces and land allocation trade-off between lot size and shopping space. Section 5 discusses general implications of the model, discusses it within the context of search theory, and considers alternative hypotheses. Section 6 concludes. An online appendix contains a discussion of some alternative specifications of the model and a technical proof.

\section{THE PARKING FEE}

In our base model, a risk-neutral monopolist shopping mall sells one good, which has no cost, at a nonnegative price of $P$. The only way to reach the mall is by car, and thus the mall has to provide parking, which costs $c>0$ per unit. The parking fee is denoted by $t$. Both $P$ and $t$ are determined by the mall, and both of them are common knowledge.

There are strictly risk-averse customers whose utility function is represented by $u(\cdot)$ with $u^{\prime}>0$ and $u^{\prime \prime}<0$. All customers have the same initial wealth of $w>0$ and the reservation value of not visiting the mall of $r>0$. The reservation value represents the savings in fuel and other search costs from looking for the good plus the value of the activity that customers can engage in instead of shopping. Each customer purchases either one or zero units of the good. The value of the good to a customer is $v$, which has the common knowledge distribution $F(v)$ with support $[0, \bar{v}]$ and density $f(v)>0 .{ }^{6,7}$ We assume that $F(v)$ has the standard monotone hazard rate property or that $f(v) /(1-F(v))$ is nondecreasing. It can be constant; thus, $f(\cdot)$ can be exponential. This implies that the shopping mall's objective function is concave. We also

\footnotetext{
${ }^{6}$ In our model, a customer has a choice between buying fixed bundle of goods and services or not. The demand curve is downward sloping because the value of this bundle differs between customers. We note that this is a standard methodology in Industrial Organization.

${ }^{7}$ In reality, $r$ differs among the customers. It depends on the distance of the customer from the store and other personal characteristics. However, allowing it to have a distribution does not change the implications while making the analysis more complicated. In such a case, the probability of shopping depends on both $v$ and $r$. This would be similar to changing the distribution of $v$ but otherwise would not have any significant effects as long as the distribution of $r$ is "well behaved." A counterexample would be if $v$ and $r$ are perfectly correlated. For example, if $r=v$, then the mall would never have any customers.
} 
assume that $\bar{v}$ is large enough that the mall can make a positive marginal profit off the highest type. This is sufficient for the mall to exist.

The critical innovation in our model is that when customers go shopping, they do not always find the good that they want. Sometimes, a customer searches all day and, in the end, leaves empty-handed. We represent this by saying that the probability that the good sold at the shopping mall is the customer's desired good is $\rho \in(0,1)$. Formally, this means that with probability $\rho$, the customer realizes that the good has value $v$ and purchases it if $v \geq P$, and with probability $1-\rho$, the good has a value of zero and the customer does not purchase it.

To understand this model more clearly, one can think of customers seeing an advertisement for the good before going shopping. The advertisement includes the price, parking fee, and a partial description. Based on this partial description, the customer estimates his value of the good before visiting the mall, $v$. When he gets to the mall, he examines the good more closely and arrives at his final value, $v z$. He buys the good if $v z \geq P$ and does not buy it otherwise. In our model, $z=1$ with probability $\rho$ and $z=0$ with probability $1-\rho$. Therefore, upon seeing the good, the customer either figures out that it is, in fact, what he wants to buy or decides it is not worth the price (i.e., his after-examination valuation is less than $P$ ) and does not buy it. In the online appendix, we examine more general distributions for $z$.

2.1. Equilibrium. Having described the economic environment, we are now in a position to calculate the equilibrium parking fee. Consider first the customer's problem. If he does not go to the shopping mall, he gets his reservation utility $u(w+r)$ with certainty. There are two possibilities if he goes to the shopping mall. He gets $v-P$ if it turns out that the good sold at the shopping mall is his desired good, but he also has to pay a parking fee of $t$. As a result, his utility in this case is $u(w+v-P-t)$, which is realized with probability $\rho$. On the other hand, he gets zero if it turns out that the good sold at the shopping mall is not his desired good, and he still has to pay the parking fee. As a result, his utility in this case is $u(w-t)$, which is realized with probability $1-\rho$. Consequently, the expected utility of visiting the shopping mall, $E(u \mid P, t)$, is

$$
E(u \mid P, t)=\rho u(w+v-P-t)+(1-\rho) u(w-t) .
$$

A customer visits the shopping mall if his expected utility of shopping is higher than his reservation utility: $E(u \mid P, t) \geq u(w+r)$, which defines the (unique) value of the good to the marginal customer who is indifferent between visiting and not visiting the shopping mall, $\tilde{v}(P, t)$ :

$$
\tilde{v}(P, t) \equiv u^{-1}\left(\frac{u(w+r)-(1-\rho) u(w-t)}{\rho}\right)-w+P+t .
$$

Here, the $u^{-1}(\cdot)$ term is the risk premium the customer must receive for shopping. Note, for future reference, that $^{8}$

$$
\tilde{v}_{P}=1 \quad \text { and } \quad \tilde{v}_{t}=1+\frac{(1-\rho)}{\rho} \frac{u^{\prime}(w-t)}{u^{\prime}(w+\tilde{v}-P-t)} \geq \frac{1}{\rho} .
$$

Now consider the mall's problem. A customer who visits the shopping mall buys a good with probability $\rho$, yielding an expected payoff of $\rho P$ to the mall. In addition, it collects $t$ from each customer who visits the shopping mall, but it costs $c$ to provide a parking space for each of them. Thus, the profit per customer is $\rho P+t-c$. Given that there are $1-F(\tilde{v}(P, t))=1-F(\tilde{v})$ customers, the mall's objective is to maximize

$$
\Pi(P, t)=[1-F(\tilde{v})](\rho P+t-c)
$$

${ }^{8}$ Here and throughout the article, we write $x_{y}$ for $\partial x / \partial y$. 
subject to the rationality constraint $\rho P+t-c \geq 0$, and that the price is nonnegative. At this point, we do not require $t$ to be nonnegative because it might be optimal for the mall to subsidize parking. In fact, this will turn out to be the case.

Since the hazard rate is nondecreasing, the objective function of the mall is concave. Ignoring the rationality and nonnegativity constraint for the moment, the first-order conditions of the problem are

$$
\Pi_{P}=-f(\tilde{v}) \tilde{v}_{P}(\rho P+t-c)+(1-F(\tilde{v})) \rho,
$$

$$
\Pi_{t}=-f(\tilde{v}) \tilde{v}_{t}(\rho P+t-c)+(1-F(\tilde{v})) .
$$

If both first-order conditions are zero, then by combining them, we can characterize the solution as

$$
\frac{\tilde{v}_{P}}{\rho}=\tilde{v}_{t}
$$

Notice that $\tilde{v}_{P} / \rho=1 / \rho$, which is the lower bound for $\tilde{v}_{t}$. To reach this lower bound, one can see from the equation for $\tilde{v}_{t}$ (Equation 3 ) that $P=\tilde{v}$, or that the price of the good is equal to the valuation of the marginal customer. Putting this condition into Equation (2) yields $t^{*}=-r{ }^{9}$

It is optimal for the mall to fully insure the marginal customer for the risk that he is taking by searching for the good. This solution requires the mall to subsidize parking even when the customer does not buy the good, which makes the implementation of this scheme infeasible. Otherwise, people will go to the mall just for the parking subsidy. This means that we have to look for a constrained solution in which the parking fee cannot be negative.

The characterization of the constrained solution is easy and entails the free provision of parking, $t^{*}=0$. We know that the monopolist mall provides the marginal customer his reservation utility, which implies that whatever the marginal customer gets in equilibrium must have a certainty equivalent of $u(w+r)$. However, the mall cannot fully insure him because full insurance requires subsidizing parking. Nonetheless, it can still employ a pricing scheme that gives him an expected utility of $u(w+r)$. The equilibrium price of the good can be derived from

$$
P^{*}=\frac{1-F(\tilde{v})}{f(\tilde{v})}+\frac{c}{\rho} .
$$

The left-hand side of this expression is strictly increasing in $P$ and the right-hand side is weakly decreasing; thus, there exists a unique $P^{*}$. The first term on the right-hand side is the standard monopoly markup. The second term guarantees that revenue is higher than costs. One may notice that everyone would buy the good if the price of the good is set to zero. However, one can easily verify that this (i.e., $P=0$ and $t>0$ ) produces lower profit than we find here. This will continue to be true throughout the article. This discussion leads to our first important result.

\section{Proposition 1 (Equilibrium Parking Fee). Free provision of parking is the unique equilib- rium.}

Notice that this result depends only on customers being risk averse; the degree of risk aversion does not matter. Thus, it holds even if the price is small relative to the customer's wealth level. It is also noteworthy that since there are no administrative or operational costs in the model,

\footnotetext{
${ }^{9}$ This is the only place in our analysis where assuming $r$ has a distribution would change our results. With such a change, full insurance would be impossible.
} 


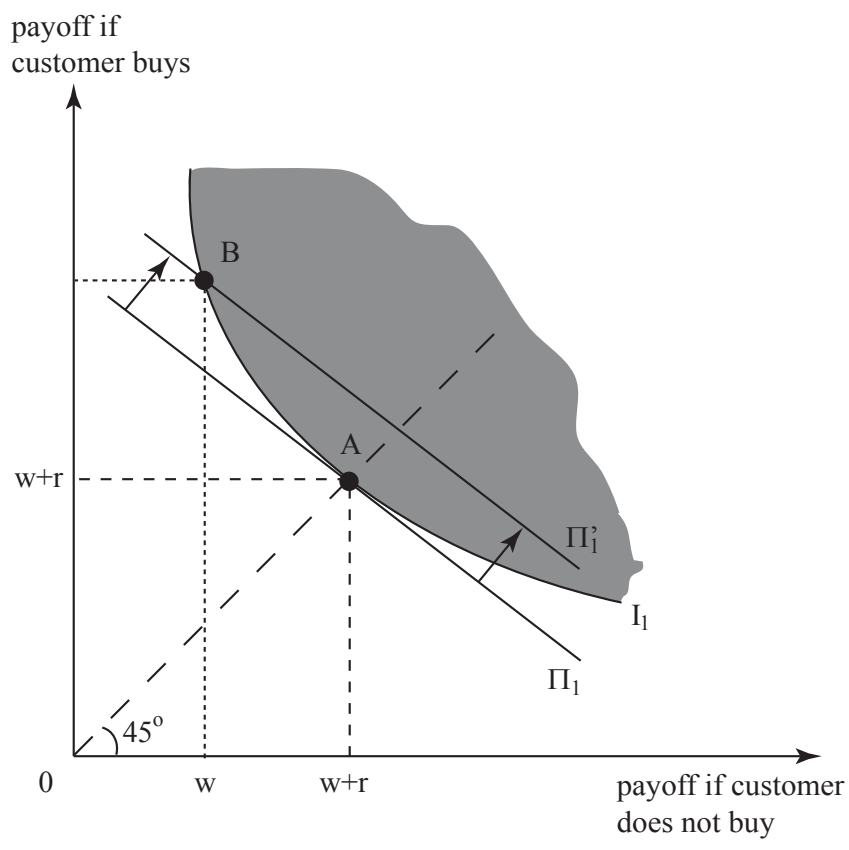

Figure 1

FREE PROVISION OF PARKING

parking is not free because of transaction costs. Finally, notice that only the marginal customers have to have $\rho<1$. If there are some customers who are certain to get what they want, they are indifferent between paying parking fees and having the fee embedded in the price of the good. The marginal customers will cause the mall to set the parking fee at zero.

For ease of explication, we call $\rho$ the customer's probability of finding his desired good; however, one can interpret $\rho$ more broadly as the probability of purchase. In that case, even when the customer is certain to find his desired good at the mall (e.g., an exact brand of an LCD TV), he might not purchase it right away, and thus his probability of purchase is less than 1 . The implications of the model are the same if customers buy a bundle of goods, some of which are sure to be found in the mall (e.g., toothpaste or bread), as long as at least one good is not found with a probability of 1 . In all of these cases, in trying to maximize its profits, the mall has incentive to "provide insurance" to the customers for the risk they face from searching.

A graphical analysis of the solution is given in Figure 1. The payoffs to customers when they buy the good are shown on the $y$-axis and when they do not on the $x$-axis. The indifference curve of the marginal customer in equilibrium is represented by $I_{1}$, which gives him a utility level of $u(w+r)$. The indifference curves of all other customers who visit the shopping mall are lined up in the shaded area. We also show two isoprofit lines of the mall, one passing through the full insurance point and another through the equilibrium point, which are denoted by $\Pi_{1}$ and $\Pi_{1}^{\prime}$, respectively. Note that $\Pi_{1}$ is associated with a higher profit level for the mall than $\Pi_{1}^{\prime}$ since it is closer to the origin, and thus gives lower payoffs to the customer. The $45^{\circ}$ line, or the certainty line, gives the set of all offers on which the customer gets the same payoff in both states of the world (i.e., when he buys or not).

The key to the unconstrained solution is that the mall is risk neutral whereas customers are risk averse. This means it is optimal for the mall to offer a price for the good and a parking fee such that the marginal customer ends up at point $A$ in Figure 1, where he gets the same payoff in both states. In this solution, the marginal customer is indifferent between visiting the shopping mall and not, and all other customers in the shaded area earn rent. The profit of the 
mall is represented by the isoprofit line $\Pi_{1}$ in this unconstrained solution. As explained before, this solution is not implementable in practice because it requires subsidizing parking.

In the constrained solution, we impose the restriction that the parking fee cannot be negative. In any such solution, the maximum attainable payoff of the customer when he does not buy the good is $w$. Among all these solutions, the best one in terms of profits is point $B$, which gives the marginal customer the maximum attainable payoff when he does not buy the good and the corresponding payoff represented by the $y$-axis of point $B$ when he buys it. In this constrained solution, as in the unconstrained solution, the marginal customer gets an expected utility of $u(w+r)$ since he is still on the same indifference curve. Yet, the profit of the mall is now lower since it moves from the isoprofit line $\Pi_{1}$ to the isoprofit line $\Pi_{1}^{\prime}$.

2.2. Welfare. Since we have found that the mall prefers providing parking for free, the natural next question is whether a social planner agrees. We assume that the social planner maximizes total welfare, $W(P, t)$, defined as the sum of customers' net utility, $U(P, t)$, and the mall's profit defined in Equation (4). Therefore,

$$
W(P, t)=U(P, t)+\Pi(P, t)
$$

where $U(P, t)$ is the integration (over the valuations of customers) of the maximum of customer's expected utility from visiting the mall and his reservation utility:

$$
U(P, t)=\int_{0}^{\bar{v}} \max [E(u \mid P, t), u(w+r)] d F(v),
$$

where $E(u \mid P, t)$ is given in Equation (1).

The derivatives of total welfare are

$$
\begin{gathered}
W_{t}=\int_{\tilde{v}}^{\bar{v}} E_{t} d F(v)+\Pi_{t}, \\
W_{P}=\int_{\tilde{v}}^{\bar{v}} E_{p} d F(v)+\Pi_{p},
\end{gathered}
$$

where $E_{p}=-\rho u^{\prime}(w+v-P-t)$ and $E_{t}=-\rho u^{\prime}(w+v-P-t)-(1-\rho) u^{\prime}(w-t)$. It is easy to establish that $W_{P}>W_{t}$ for all $P \geq 0$ and $t \geq 0$. We know from the equilibrium analysis above that $\Pi_{P}>\Pi_{t}$ in this range, and $E_{t}<E_{p}$. Thus, the socially optimal parking fee is also zero.

This is, of course, the social optimum in a second-best sense. By removing the constraint $t \geq 0$, we can find the first-best parking fee and show that it is less than $-r$. In the unconstrained equilibrium (where $\Pi_{P}=\Pi_{t}=0$ ), both $W_{P}$ and $W_{t}$ are negative, meaning that both the price of the good and the parking fee of the unconstrained solution $\left(t^{*}=-r\right)$ are too high. Therefore, the first-best social optimum requires subsidizing free parking, but for the reasons explained in the mall's problem, such a solution would be difficult to implement. This leads to the secondbest optimum in which parking is free. We record the results of this discussion in the following proposition.

Proposition 2 (Social Optimum). Free provision of parking is socially optimal in a secondbest sense, but the price of the good that the mall charges is too high because of its monopoly power.

One may wonder how embedding the costs of parking in the price of the good can be efficient. After all, it is much like an excise tax. The basic point is that raising the parking fee is more 
distortionary than raising the price; thus, society (and the mall) prefers raising the price of the good. In general, there are two types of distortions caused by excise taxes. The first one is exclusionary, those who should purchase do not. The second is demand suppressing, each customer buys less than the optimal amount. Due to our fixed proportions assumption, we do not consider the second type of distortion-only the first. And raising the parking fee drives away customers "twice"-once when they buy the good and once when they do not, or, in other words, more than raising the price.

A more precise intuition is as follows: The unconstrained socially optimal price is

$$
P=\frac{1}{\rho f(\tilde{v})} \int_{\tilde{v}}^{\bar{v}} E_{P} d F(v)+\frac{1-F(\tilde{v})}{f(\tilde{v})}+\frac{c}{\rho} .
$$

Notice that this is lower than the monopolist's price because $\int_{\tilde{v}}^{\bar{v}} E_{P} d F(v)<0$. Thus, the summation of the first two terms may be negative because society wants to encourage individuals to shop, but to the first order, this is independent of the cost of parking. Hence, we can look at the last term in isolation. For each unit of parking that a customer consumes, society wants him to pay $c / \rho$. Thus, he pays more than the cost of a unit of parking. Although we encourage the reader to think of high $\rho$, for the sake of argument, consider a very small $\rho$ such as $\rho=1 / 5$. Then, when a customer buys the good, he is paying for five parking spaces. Consider the alternative of having everyone pay the marginal cost of the goods they consume, or $P=0$ and $t=c$. Compared to this alternative, the price seems distortionary because it seems that many individuals are being excluded from consuming the good. The key to understanding our results is realizing that this is not true. Risk aversion implies that customers are so worried that a lot of them will decide not to shop, more so than in the true social optimum.

This welfare analysis does not include the social costs of parking. Shoup (2005) argues that the high cost of parking is due to social costs that stem from congestion and pollution externalities. One may be tempted to think that such social costs may encourage the social planner to charge positive parking fees. After all, it is the shopping (which always results in parking) that causes the social costs, not the purchasing. We have analyzed this in a reduced-form model and found this not to be the case. To understand why consider the intuitive method of having the social planner tax the mall to cover these externalities. This would then increase the cost of a unit of parking, but as we have already shown, the mall would pass on these expenses to the customer through the price, and society would agree with this. Nevertheless, a full analysis of this issue requires embedding our model in a model of congestion or cruising externalities and is beyond the scope of this article.

We think that our results would continue to hold in more general settings. For example, if there are heterogeneous customers who each wants only one of a set of goods, then welfare could be expressed as the sum of welfare for each good, and the results above would immediately generalize. A more difficult case would be if customers were homogeneous but wanted to buy multiple individually priced goods. This would give rise to interesting cross subsidization issues - which good's price should bear the brunt of the cost of parking? ${ }^{10}$ Based on our analysis, we can conclude that both society and the mall would like parking to be free. However, we cannot be sure if this solution can always be implemented. Notice that if customers want to consume an infinite number of goods, then the insurance motive would disappear, but only in the limit. Since our results do not depend on the degree of risk aversion for any large finite number, parking would be free. We also do not see any reason the results would not continue to hold for more general cost functions.

\footnotetext{
${ }^{10}$ If the goods are sold by different stores, there could also be positive externalities among them. Anchor stores, for example, attract customers to the mall, which has a positive externality on other stores (see Konishi and Sandfort, 2003).
} 
2.3. Parking Validation. The reader might be disturbed by the inequity of free parking. After all, everyone who comes to the shopping mall raises the mall's costs. Why do some get off without paying for it? Perhaps, if the mall used parking vouchers, this would give the mall an incentive to charge nonbuyers. However, it turns out that parking vouchers do not change the mall's incentives. It may now either subsidize buyers for parking or not charge them at all, but nonbuyers will still park for free. Free provision of parking is an equilibrium even when validation is allowed. More importantly, if there were transaction costs associated with collecting parking fees, free provision of parking would be the only equilibrium. In fact, ICSC and ULI (2003) report that $86 \%$ of shopping malls do not have a parking validation program.

In a parking validation system, customers can validate their parking ticket when they buy a good. This allows the mall to charge a different parking fee to the customers who buy a good than to those who do not. Let the parking fee when a customer buys a good be $t_{b}$ and that when he does not be $t_{n b}$. Now, the marginal customer's valuation is given by ${ }^{11}$

$$
\tilde{v}\left(P, t_{b}, t_{n b}\right) \equiv u^{-1}\left(\frac{u(w+r)-(1-\rho) u\left(w-t_{n b}\right)}{\rho}\right)-w+P+t_{b} .
$$

Note that $\tilde{v}_{P}=\tilde{v}_{t_{b}}=1$ and $\tilde{v}_{t_{n b}}=((1-\rho) / \rho) u^{\prime}\left(w-t_{n b}\right) / u^{\prime}(w+\tilde{v}-P-t) \geq(1-\rho) / \rho$.

The mall's maximization problem is

$$
\max _{P, t_{b}, t_{n b}}(1-F(\tilde{v}))\left(\rho P+\rho t_{b}+(1-\rho) t_{n b}-c\right) .
$$

By setting the first-order conditions with respect to $P$ and $t_{n b}$ to zero, we get $((1-\rho) / \rho) \tilde{v}_{P}=\tilde{v}_{t_{n b}}$. Again, the right-hand side is the lower bound for $\tilde{v}_{t_{n b}}$ and $t_{n b}^{*}=-r$, but as before this solution is not implementable and thus $t_{n b}^{*}=0$. Customers would not validate their parking ticket if $t_{b}>t_{n b}$, so we can conclude that $t_{b}^{*} \leq 0$, or, in words, the mall either subsidizes buyers' parking or provides it for free.

The price of the good and the parking fee for buyers are not uniquely determined:

$$
P^{*}+t_{b}^{*}=\frac{1-F(\tilde{v})}{f(\tilde{v})}+\frac{c}{\rho} .
$$

However, the equilibrium payoffs will always be as in the base model. All solutions are represented by point $B$ in Figure 1 . If the mall subsidizes buyers' parking, then this subsidy will increase the price of the good in a one-to-one ratio. That is, it may appear to be helping out the buyers, but it is indeed just transferring a fee between the two prices. The following proposition summarizes our findings.

Proposition 3 (PARKING VALIDATION). Free provision of parking is an equilibrium even when parking validation is allowed. The mall can either charge no parking fees at all or provide free parking to those who do not validate their tickets while subsidizing the rest upon validation.

Nonetheless, we should point out that there are interesting second-order reasons to subsidize buyers. One should recognize that most of the costs of shopping are fixed-the costs of driving to the store and other things. If customers differ in the amount of goods they want to buy, providing them a fixed subsidy for any purchases will encourage them to shop. This insight is already being implemented. A recent JC Penney catalog has a $\$ 10$ off coupon for a purchase of $\$ 10$ or more.

\footnotetext{
${ }^{11}$ In this section and in the rest of the article, we uniformly use the same notation of the base model: $\tilde{v}$ for valuation of the marginal customer, $\Pi$ for profit of the mall, $U$ for the sum of customers' net utility, and $W$ for total welfare. We shall use superscripts or decorations when the possibility of confusion arises.
} 
2.4. Competitive Pricing. The reader may also be concerned that the results depend on the mall being a monopolist. Perhaps if it was not able to extract supranormal profits using the price, it could not afford free parking. We partially respond to this concern by assuming that the price of the good is determined competitively (i.e., it is not a function of demand). We assume that the shopping mall is composed of many stores, each of which offers one unit, and that the stores are Bertrand competitors. This moves us toward analyzing the shopping mall as a two-sided market.

Assume that the mall requires a profit of $\pi>0$ per customer. We do not optimize over $\pi$ because it would be the same as optimizing over $\rho P+t-c$. Instead, we assume that it is fixed, perhaps as a result of competition with other shopping malls in the area. The outside option of visiting other shopping malls could, in a reduced form, be part of what determines the reservation value of not visiting the given mall. The exact size of $\pi$ is not important for our analysis as long as it is strictly positive.

Formally, the mall can determine the parking fee, $t$, and charge the stores a rent, $R=\pi+c-t$. The stores then compete by choosing their prices, resulting in an equilibrium price for the good of $P=R / \rho$. The mall then maximizes its profit given by

$$
\Pi(\pi, t)=(1-F(\tilde{v})) \pi
$$

where $\tilde{v}$ is the same as in Equation (2).

The constraints for this model are $P=R / \rho$ and $t \geq 0$. After replacing $P$ by $R / \rho$, we get

$$
\Pi_{t}=f(\tilde{v}) \pi\left(\frac{\tilde{v}_{P}}{\rho}-\tilde{v}_{t}\right) .
$$

This expression is strictly negative, implying that the equilibrium parking fee is zero. To see this, notice that if $\tilde{v}>P$, then $\tilde{v}_{P} / \rho<\tilde{v}_{t}$, and $\tilde{v}>P$ if $t \geq 0$, thus $t=0$. The following proposition records this result.

Proposition 4 (COMPetitive Pricing). Free provision of parking is an equilibrium even when the price of the good is set competitively.

2.5. A Simple Institutional Model. We now move closer to a full two-sided market model of the shopping mall (Rochet and Tirole, 2003). Here, we incorporate the fact that most stores in shopping malls are chains and have their prices set at the national level. It turns out that the mall still chooses its rental rate to maximize Equation (4) under these specifications.

Since this is not a full equilibrium analysis, we take as a primitive that these chains charge widely dispersed prices. For example, brand name jeans are frequently sold for multiples of the price of generic jeans. On the other hand, stores within a mall will be competing strongly with each other; thus, we continue to assume Bertrand competition within the mall. For simplicity, we maintain our assumption that a store will only supply one unit of the good. Finally, in order to avoid constraining the shopping mall, we assume that for every price, there is a sufficient supply of chain stores to meet the demand in the mall's region.

Let $R$ be the rental rate charged by the shopping mall. Then, firm $j$ wants to enter if $\rho P_{j} \geq R$. However, within-mall competition guarantees that if $\rho P_{j}>R$, then this firm must lower its price. In equilibrium, all firms that enter will have $\rho P_{j}=\rho P=R$. Since supply must equal demand, we will have $(1-F(\tilde{v})) \rho$ firms enter, resulting in Equation (4). One of the implications of this extension is that the prices and brands available in shopping malls are higher priced than goods available outside. Casual empiricism readily supports this insight. Clearly, there could be other reasons for this such as reduced search costs. 


\section{PARKING LOT SIZE}

We now extend the base model to analyze the equilibrium size of a parking lot. In the base model, the equilibrium lot size is just enough to meet total demand. In order to make parking lot size a meaningful choice variable, demand must vary. Then, the mall must choose between a large lot that is rarely used or a small one that is usually full. The ICSC and ULI (2003) survey strongly supports the hypothesis that demand varies. It inquired if and when the parking lot is at capacity, and $57 \%$ responded that it sometimes was. This occurred on weekends, holidays, days before forecasted snow, back-to-school sales, and the Christmas shopping season.

Motivated by the survey findings, we assume that the total possible demand, $M$, is a random variable with distribution $G(M)$ and density $g(M)$ for $M \in[\underline{M}, \bar{M}]$ where $\underline{M}>0$. The base model is the special case in which $M=1$ with probability 1 . To assure concavity of the mall's profit function and uniqueness of the equilibrium, in addition to the monotone hazard rate property of the distribution of $v$, we impose that the hazard rate of the distribution of $M$, $g(M) /(1-G(M))$, is higher than $1 / M$ for all $M \in[\underline{M}, \bar{M}]$. This is similar to assuming that the total potential demand is not too dispersed.

We assume that the price of the good, the parking fee, and the lot size have to be determined before $M$ is realized and thus cannot depend on $M$. This assumption is clearly reasonable for both the parking fee and the lot size. If we did not assume it for the price, then the price would rise in high demand periods to clear the market. However, retailers are apparently constrained to not raise the price to clear the market. This alternative would also predict that prices should rise during the high demand season of Christmas, and most particularly on Black Friday-the traditional start of the season. In contrast, there are almost always sales on Black Friday and often during the entire Christmas shopping season. Hence, we believe that our assumption is reasonable for the price of the good.

The parking lot size is denoted by $l$. Customers know both their valuations of the good and total possible demand. If the demand is higher than the lot capacity (i.e., $M(1-F(\tilde{v}))>l$ ) and yet customers' valuation of the good is sufficiently high (i.e., $v \geq \tilde{v}$ ), then we assume that they decide to go to the shopping mall with the appropriate probability so that exactly a mass $l$ of customers visits the shopping mall, or there is random rationing.

Assuming that customers randomize before visiting the shopping mall is a simplifying assumption. This keeps $\tilde{v}$ given in Equation (2) unchanged. In the online appendix, we work out two other reasonable alternatives. In the first, all customers with $v \geq \tilde{v}$ decide to go to the shopping mall, but some will have to leave because they cannot find a parking space (first-in-first-served rationing). In the second, among all customers with $v \geq \tilde{v}$, only those who have higher valuations for the good decide to go shopping (efficient rationing). Under both of these alternative specifications, the key results of this section are qualitatively the same.

3.1. Equilibrium. Given our assumptions, there are two possibilities: Either all individuals who demand the good can shop at the mall or the parking lot saturates and some customers cannot visit the mall. Therefore, the effective demand for the shopping mall is $\min [M(1-F(\tilde{v})), l]$, and consequently, the expected demand, $D(P, t, l)$, is

$$
\begin{aligned}
D & (P, t, l)=\int_{\underline{M}}^{\bar{M}} \min [M(1-F(\tilde{v})), l] d G(M) \\
& =(1-F(\tilde{v})) \int_{\underline{M}}^{\tilde{M}} M d G(M)+l \int_{\tilde{M}}^{\bar{M}} d G(M)
\end{aligned}
$$




$$
=G(\tilde{M})(1-F(\tilde{v})) E[M \mid M \leq \tilde{M}]+(1-G(\tilde{M})) l,
$$

where $\tilde{M}(1-F(\tilde{v}))=l$, and $E[M \mid M \leq \tilde{M}]$ represents the expected value of $M$ for $M \leq \tilde{M}$. Equations (19)-(21) provide $D(P, t, l)$ in three different forms; the first is the raw form. It is easier to obtain some derivatives of concern by using Equation (20) and more intuitive to provide some expressions in the form of Equation (21). Using $\tilde{M}(1-F(\tilde{v}))=l$, one can verify that $D_{P}=$ $-f(\tilde{v}) G(\tilde{M}) E[M \mid M \leq \tilde{M}]<0, D_{t}=-f(\tilde{v}) \tilde{v}_{t} G(\tilde{M}) E[M \mid M \leq \tilde{M}]<0$, and $D_{l}=1-G(\tilde{M})>0$. The profit function of the mall is

$$
\Pi(P, t, l)=D(P, t, l)(\rho P+t)-l c .
$$

We subtract $l c$ from the revenue because the cost of a parking lot is determined by the size of the lot, not by how much of it is used. Notice that if there were no uncertainty, then $D(P, t, l)=l$ and this equation would be the same as the base model. The profit maximization problem is still subject to similar rationality and nonnegativity constraints. It should be clear that $l=\bar{M}(1-F(\tilde{v}))$ only if $c=0$, because if $l=\bar{M}(1-F(\tilde{v}))$, then there is no benefit of increasing the parking lot size. It should also be clear that $l>M(1-F(\tilde{v}))$ because otherwise $D(P, t, l)=l$ and there is no cost to raising the fees.

Setting $\Pi_{P}=\Pi_{t}=0$ yields $\tilde{v}_{P} / \rho=\tilde{v}_{t}$, which means $t^{*}=-r$. Thus, once again, we get $t^{*}=0$. Given this, there is no problem in setting $\Pi_{l}=0$. The first-order condition with respect to $l$ represents the marginal benefit of an additional parking space minus the marginal cost of it. The marginal benefit is the probability that the parking space is used times the revenue from that space if it is used. The probability is the probability $M>\tilde{M}$, or $1-G(\tilde{M})$. This yields the equilibrium lot size:

$$
l^{*}=G^{-1}\left(1-\frac{c}{\rho P}\right)(1-F(\tilde{v}))
$$

Notice that another way of writing this condition is $G(\tilde{M})=1-c /(\rho P)$. From this, we can see that $\rho P \geq c$, and the profit of the mall is positive. Finally, the equilibrium price of the good is

$$
P^{*}=\frac{1-F(\tilde{v})}{f(\tilde{v})}\left(1+\frac{(1-G(\tilde{M})) \tilde{M}}{G(\tilde{M}) E[M \mid M \leq \tilde{M}]}\right)
$$

and the equilibrium $\left(P^{*}, t^{*}, l^{*}\right)$ is unique. ${ }^{12}$ The following proposition summarizes the results of this section.

Proposition 5 (Lot Size Model-Equilibrium). If the demand to go to the shopping mall varies, then

(i) the equilibrium parking fee is zero,

(ii) the equilibrium price of the good satisfies Equation (24), and

(iii) the equilibrium lot size is given by Equation (23).

3.2. Welfare. Let us now turn to welfare analysis. Our main goal here is to understand minimum parking requirements. Minimum parking requirements exist all over the world. They specify the minimum amount of parking that must be provided by any land use.

\footnotetext{
${ }^{12}$ When there is no demand uncertainty, this price expression boils down to Equation (8) of the base model. First, recognize that in this case, $E[M \mid M \leq \tilde{M}]=\tilde{M}$. Then, using $G(\tilde{M})=1-c /(\rho P)$ in Equation (24) results in $P^{*}=$ $\left[(1-F(\tilde{v}))\left(\rho P^{*}\right)\right] /\left[f(\tilde{v})\left(\rho P^{*}-c\right)\right]$. After manipulation, we arrive at Equation $(8)$.
} 
As in the base model, we define welfare, $W(P, t, l)$, as the sum of customers' net utility, $U(P, t, l)$, and the mall's profit, $\Pi(P, t, l)$. The latter is defined in Equation (22) and the former is given by

$$
U(P, t, l)=\int_{\underline{M}}^{\bar{M}} M \int_{0}^{\bar{v}} \max [\alpha E(u \mid P, t)+(1-\alpha) u(w+r), u(w+r)] d F(v) d G(M)
$$

where $E(u \mid P, t)$ is the expected utility given in Equation (1), and $\alpha$ is the probability of visiting the shopping mall, which we calculate next.

According to our assumptions, customers whose valuations are higher than $\tilde{v}$ decide to go to the shopping mall with the appropriate probability so that exactly a mass $l$ of them try to purchase the good. This probability is 1 when there is sufficient number of parking spaces for all of them. Otherwise, when $M>\tilde{M}$, there will be only $l$ parking spaces but $M(1-F(\tilde{v}))>l$ individuals who demand them. Therefore, the probability of visiting the shopping mall should be $l /(M(1-F(\tilde{v})))$ in this case. Both cases can be summarized with the following probability measure:

$$
\alpha=\frac{\min [M(1-F(\tilde{v})), l]}{M(1-F(\tilde{v}))} .
$$

The utility expression given in Equation (25) deals with all cases simultaneously. If demand is low (i.e., $M \leq \tilde{M}$ ), $\alpha=1$ and those whose valuations are higher than $\tilde{v}$ visit the shopping mall and obtain $E(u \mid P, t)$, whereas those whose valuations are less than $\tilde{v}$ do not visit the shopping mall and obtain $u(w+r)$. If total demand is high (i.e., $M>\tilde{M}$ ), those whose valuations are less than $\tilde{v}$ still do not visit the shopping mall and obtain their outside option. However, this time, there are not enough parking spaces to fulfill the demand of those with $v>\tilde{v}$, and so each individual will go to the shopping mall with probability $\alpha=l /(M(1-F(\tilde{v})))$. When this happens, by the law of large numbers, we expect to see exactly $l$ individuals showing up in the parking lot.

We know that $\Pi_{l}(P, t, l)=0$ at the mall's profit-maximizing choice of lot size. Thus, the derivative of the welfare function with respect to the lot size at the profit-maximizing lot size, denoted by $\left.W_{l}\right|_{\Pi_{l}=0}$, is simply $U_{l}(P, t, l)$ :

$$
\begin{aligned}
\left.W_{l}\right|_{\Pi_{l}=0}=U_{l} & =\int_{\tilde{M}}^{\bar{M}} M \int_{\tilde{v}}^{\bar{v}} \frac{E(u \mid P, t)-u(w+r)}{M(1-F(\tilde{v}))} d F(v) d G(M) \\
& =(1-G(\tilde{M})) \int_{\tilde{v}}^{\bar{v}} \frac{E(u \mid P, t)-u(w+r)}{1-F(\tilde{v})} d F(v)>0 .
\end{aligned}
$$

Note that the outer integral in the first line is over $[\tilde{M}, \bar{M}]$ because if the size of the parking lot is nonbinding, then increasing the lot size has no impact on welfare. The second line is easier to interpret. To understand it, note that customers are hurt only if the size of the parking lot is binding, which occurs with probability $1-G(\tilde{M})$. A customer with value $v$ loses $E(u \mid P, t)-$ $u(w+r)$ by not being able to shop, and since only the customers with values in $[\tilde{v}, \bar{v}]$ suffer this loss, the expected loss to the average customer is the integral term.

Equation (27) says that the full social optimum requires a larger parking lot size than the market equilibrium. However, this requires price controls in addition to controlling the lot size. If the social planner cannot control the price of the good, then imposing a larger lot size could increase the price of the good, which would diminish or reverses the welfare-improving effects 
of increased lot size. However, as shown in the online appendix, this does not happen. One of the implications of a concave objective function is that $\partial P / \partial l$ is negative. When $l$ is increased, the potential pool of customers is increased. Thus, decreasing the price by a small amount results in a larger increase in demand, and therefore the profit-maximizing price is lower. This means that increasing the lot size improves welfare even when the social planner cannot impose price controls. This leads to the following important result.

Proposition 6 (Foundations of Minimum Parking Requirements). If the demand to the shopping mall varies, the lot size it chooses is smaller than the socially optimal lot size, whether or not the social planner controls the price of the good.

To our knowledge, this proposition is the first theoretical attempt to explore the foundations of minimum parking requirements. The intuition behind the result is straightforward. The social planner cares about the loss of utility of those who would like to purchase the good but cannot. The mall cares only about the effect of this on its profits. Thus, the social planner always wants a larger lot size. If we make the simplifying assumption that society sets the price, the equation for the optimal lot size, $l^{o}$, is

$$
l^{o}=G^{-1}\left(1-\frac{c}{\rho P}+\frac{U_{l}\left(P, t, l^{o}\right)}{\rho P}\right)(1-F(\tilde{v})),
$$

which clearly shows that the social planner wants to increase the lot size to take into consideration the loss of utility of the customers.

We should note that if there were a social cost to parking, it might change this result, which may potentially result in society wanting to impose a maximum parking lot size. However, as Arbatskaya et al. (2007) point out, this cost should be subdivided into two costs, a flow cost and a cruising (or queuing) cost. The former is a cost of traffic congestion as individuals are going to the mall; the latter is the social cost imposed by them searching for a parking space or coming early. The social cost of flow should be increasing in $l$, with a form like $S C^{f}(\min [M(1-F(\tilde{v})), l])$ but the social cost of cruising should be decreasing in $l$, with a form like $S C^{c}(\max [M(1-F(\tilde{v}))-l, 0])$. Thus, whether the net marginal cost of $l$ is decreasing or increasing must be decided by balancing out these two impacts.

An important question is how binding our optimal minimum parking requirement is. One thing that is immediately clear is that society should want the parking lot to be full occasionally. The parking lot should not be large enough to satisfy peak demand. Unfortunately, as reported by Shoup (1999), satisfying the peak demand is the standard stated objective. Instead, we are arguing for mild requirements. We have found out that the ratio of the probabilities that the lot is full depends only on demand characteristics and the average amount spent. Assuming that the utility is CARA $\left(u(w)=-e^{-\sigma w}\right)$, the distribution of values is exponential, and using the figures in Connolly and Rogoff (2008) for the conversion rate and the average amount spent in a shopping mall, one concludes that society wants to decrease the probability the lot is full by less than $5 \%$.

It is clear that municipalities do not actually require malls to provide enough parking for peak demand. According to the ICSC and ULI (2003) survey, 57\% of malls sometimes had full parking lots. Whether minimum parking requirements are too high or too low is clearly an empirical issue. Cutter and Franco (2012) analyze this issue for the municipalities in Los Angeles county and found that for retail outlets, they were not even binding. ${ }^{13}$ Almost all stores chose to have more parking than required. This indicates that either the minimum parking requirements are too low or that customers punish stores with too little parking by not going back. If it is the former, then they should be increased; if it is the latter, there may be a serious problem. Land use may be distorted because customers' expectations are too high.

${ }^{13}$ They do not analyze shopping malls because the regulations are too complex. 
In general, shopping malls have to provide four parking spaces per 1,000 square feet of gross leasable area. As Shoup (1999) correctly points out, no one knows why. We provide a rational, but we cannot say whether this rule of thumb represents an approximately optimal solution. An empirical assessment based on our theory is needed at this point.

\section{THE URBAN MALL}

Although the models in Sections 2 and 3 explain the situation for most shopping malls, they do not capture two critical issues that malls may face in urban areas. We address these issues here. First, in an urban area, individuals may want to use the mall's parking lot for other purposes-to go to a park, restaurant, or store that is not in the shopping mall. Second, the mall has a fixed bound on the amount of space its property can take, so it has to decide what share of that space to devote to parking. We think that this is more of an issue for urban malls, as land is quite expensive in urban areas, whereas it is negligible for suburban malls.

In order to facilitate comparison with the base model, we analyze these two features one at a time. Section 4.1 shows that if individuals want to use the parking lot for other purposes, then the mall may want to charge positive parking fees. Section 4.2 shows that if the mall has a trade-off between parking and shopping spaces, parking is still provided for free but society may want to impose maximum parking requirements.

4.1. Positive Parking Fees. One question that we have not answered is why we observe positive parking fees in urban areas. In an urban mall, there may be individuals who have no intention of shopping at the mall but park in the lot. They may want to go somewhere in the urban area that does not have its own parking and use the mall's lot for convenience.

In this variation of our model, customers will have two decisions to make: whether to go to the urban area and whether to shop at the shopping mall. We continue to denote their reservation value of not going to the urban area with $r$. But now, individuals get an additional payoff of $n>0$ if they go to the urban area but not to the mall. Therefore, their reservation payoff becomes $r+n$. In order to achieve this value, they must park in the mall's parking lot and pay the parking fee $t$. We assume that $n>c$ so that it can be profitable to provide parking to nonshoppers. For simplicity, we assume that if an individual goes to the urban area, he can either shop at the mall or do some alternative activity, but he cannot do both.

Notice that $n$, like $r$, should have a distribution. Clearly, different individuals will have different reasons for going to the urban area and thus have different values for these alternative activities. This would have two impacts on the results. First, like in the standard model, a customer's decision on whether to go to the mall is now based on $n$; thus, it will be more complicated but will be otherwise unchanged. Second, there would be a demand for parking that depended on $n$. Because we expect that neither of these changes would substantially alter the core insight, we shall work with the simpler model. Since we do not want to consider a distribution for $n$, we will also assume that the mall can provide parking for all who want it.

We start off by showing that $t>n$ cannot happen in any equilibrium. In such a case, all those who park in the lot would be shoppers because $u(w+r+n-t)<u(w+r)$. But then, we immediately see that the mall would like to decrease the parking fee due to the "insurance" motive in maximizing its profit. This means that the mall does not want a parking fee higher than $n$. Thus, in any equilibrium, it must be that $t \leq n$, in which case all individuals go to the urban area because $u(w+r+n-t) \geq u(w+r)$.

An individual shops at the mall if $E(u \mid P, t) \geq u(w+r+n-t)$. The valuation of the marginal customer in this case is

$$
\tilde{v}(P, t) \equiv u^{-1}\left(\frac{u(w+r+n-t)-(1-\rho) u(w-t)}{\rho}\right)-w+P+t
$$


For future reference, note that $\tilde{v}_{P}=1$ and $\tilde{v}_{t}=\left[(1-\rho) u^{\prime}(w-t)-u^{\prime}(w+r+n-t)\right] /\left[\rho u^{\prime}(w+\right.$ $\tilde{v}-P-t)]+1$. It is no longer possible for us to find a lower bound for $\tilde{v}_{t}$; indeed as $\rho$ goes to one $\tilde{v}_{t}$ can become negative. We will show that if $\tilde{v}_{t} \leq 1 / \rho$, then $t^{*}=n$.

Since $t \leq n$, the shopping mall always has a parking demand of 1 . Thus, the mall earns $t$ per customer and incurs a cost of $c$ per customer no matter what. Some of the individuals using the lot shop at the mall, and each of those gives a revenue of $\rho P$. This means that the profit of the mall, $\Pi(P, t)$, is

$$
\Pi(P, t)=(1-F(\tilde{v})) \rho P+t-c .
$$

The first-order conditions of the mall's profit maximization problem are

$$
\begin{aligned}
\Pi_{P} & =-f(\tilde{v}) \tilde{v}_{P} \rho P+\rho(1-F(\tilde{v})), \\
\Pi_{t} & =-f(\tilde{v}) \tilde{v}_{t} \rho P+1 .
\end{aligned}
$$

Then, the equilibrium price of the good is determined by

$$
P^{*}=\frac{1-F(\tilde{v})}{f(\tilde{v})} \text {. }
$$

Plugging this into the derivative with respect to $t$, we find that $\Pi_{t}=-(1-F(\tilde{v})) \rho \tilde{v}_{t}+1$. Since $1-F(\tilde{v}) \leq 1$, we know that $\Pi_{t} \geq-\rho \tilde{v}_{t}+1$, and the left-hand side of this expression is positive if $\tilde{v}_{t} \leq 1 / \rho$. This may not be true if individuals are very risk averse and $\rho$ is small. However, remember that $\tilde{v}_{t}$ is decreasing in $\rho$, and in the limit, it is actually negative. Thus, if $\rho$ is large enough, this condition is satisfied, and we find that $t^{*}=n$. This should be considered the normal case. After all, $\rho$ is the probability that customers find what they want at the mall. If it is too low, then the mall is doing something wrong. This gives us the following result.

Proposition 7 (Positive Parking Fees). If the probability of customers being able to purchase the good is high enough, then the equilibrium parking fee is positive, i.e., $t^{*}=n$.

Therefore, positive parking fees can happen in equilibrium if individuals are able to free ride on the mall's parking spaces. There is indeed a range of $\rho$ values such that $0<t^{*} \leq n$. Here, we focus only on $t^{*}=n$ since it is sufficient to show the underlying reason for a positive parking fee. To understand this result intuitively, first notice that if $\tilde{v}_{t} \leq \tilde{v}_{P} / \rho=1 / \rho$, then the mall is driving more customers away by increasing the price of the good than it is by increasing the parking fee. Why is this? When the mall increases the parking fee, it also makes the outside option less desirable, giving these individuals more of an incentive to shop at the mall. Notice that if $n$ had a distribution, then the shopping mall would essentially face two demand curves, one for the good and one for parking. In this case, determining the optimal parking fee will essentially be an independent profit maximization problem, and that is why we think that it would not meaningfully alter results.

Another way to understand positive parking fees is to look at the three groups of individuals who park in the lot. The first group is the "winners" who shopped at the mall and found what they wanted. This group has a mass of $\rho(1-F(\tilde{v}))$ and is indifferent over all parking fees since a higher parking fee is compensated with a lower price for the good. The second group is the "losers" who shopped and did not find what they wanted. They do not want to pay for parking since they are leaving empty-handed and, because of its insurance motive, the mall does not want to charge them. This group has a mass of $(1-\rho)(1-F(\tilde{v}))$. Finally, unlike in suburban malls, there is a third group-the "nonshoppers" - who only want to park. They have a mass of $F(\tilde{v})$. The only way to get any revenue out of nonshoppers is to charge a parking fee. As $\rho$ 
gets large enough, the incentive not to charge losers is outweighed by the incentive to charge nonshoppers.

One might notice that $P$ and $t$ are never affected by the cost of providing a parking space. This is because, as long as the mall decides to provide parking to all individuals, the cost of providing parking is essentially fixed, and like all fixed costs, it has no effect on optimized values.

4.2. Lot Share: From Too Little to Too Much. In the extended base model, the mall is making four decisions. It chooses the price for the good, the parking fee, the parking lot size, and the size of the shopping area. We have simplified the analysis by ignoring the last of these choices, but clearly, the benefit of a larger store is that the probability that a customer finds the good that he wants increases. In an urban area, increasing the size of the stores may require decreasing the size of the parking lot. We investigate this trade-off here.

We assume that the shopping mall occupies a fixed amount of land and that the mall must decide how much of this land to allocate to parking. Notice that, in this model, there must be vertical and horizontal limits on the size of the property. The horizontal limits may be imposed because the cost of acquiring more land is prohibitive. The vertical limit may be imposed by increasing costs as the building gets taller or by government regulations.

We shall employ the simplest characterization of the trade-off between space allocated to parking and shopping. We assume that the shopping mall occupies a unit of land. Let the share of land allocated to parking be $s$, and therefore the share of land allocated to shops is $1-s$, where $s \in[0,1]$. We assume that increasing $s$ decreases "good variety" offered, which thus will decrease the probability that a customer finds the good that he wants. We assume that $\rho(s) \in(0,1)$ satisfies $0<\rho(0)<1,-\rho(s) / s<\rho^{\prime}(s)<0, \rho^{\prime \prime}(s)<0$. That is, the probability of finding the desired good at the shopping mall is a monotonically decreasing and strictly concave function of $s$. Notice that this means that the probability of finding the desired good is strictly increasing in shop size $(1-s)$ and also concave, representing a diminishing marginal benefit from increasing the land allocated to shops. It seems natural that increasing the variety of goods in the mall should increase the probability that a customer finds what he wants, but there will naturally be some satiation in the process. The assumption that $\rho(0)>0$ along with the assumption that $\bar{v}$ is high enough guarantees that the solution is interior, and $-\rho(s) / s<\rho^{\prime}(s)$ guarantees that the first-order conditions are well behaved.

The marginal customer is now defined by

$$
\tilde{v}(P, t, s) \equiv u^{-1}\left(\frac{u(w+r)-(1-\rho(s)) u(w-t)}{\rho(s)}\right)-w+P+t .
$$

The maximization problem of the mall is

$$
\max _{P, t, s} \min [1-F(\tilde{v}), s](\rho(s) P+t)-c s
$$

Notice that in any solution, $s=1-F(\tilde{v})$, just like in the base model. Given this constraint, the maximization problem can be rewritten as

$$
\max _{P, t}(1-F(\tilde{v}))(\rho(1-F(\tilde{v})) P+t-c)
$$

The first-order conditions of this problem are

$$
\begin{gathered}
\Pi_{P}=-f(\tilde{v}) \tilde{v}_{P}\left[\left(\rho+(1-F(\tilde{v})) \rho^{\prime}\right) P+t-c\right]+(1-F(\tilde{v})) \rho, \\
\Pi_{t}=-f(\tilde{v}) \tilde{v}_{t}\left[\left(\rho+(1-F(\tilde{v})) \rho^{\prime}\right) P+t-c\right]+(1-F(\tilde{v})),
\end{gathered}
$$


and like before in order for both of them to be equal to zero, we need $\tilde{v}_{P} / \rho=\tilde{v}_{t}$. The difference between the analysis in this section and in our base model is that the supply of parking space is no longer perfectly elastic. The mall trades off increased lot size with decreased good variety. This is the reason for the appearance of $\rho^{\prime}(s)$ in the equations above. If one assumes that $\rho^{\prime}(s)=0$, then the first-order conditions are identical to those in the base model. This is equivalent to increasing the lot's size until the impact of $s$ on $\rho(s)$ is negligible.

Given the equilibrium condition $s=1-F(\tilde{v})$, the formulas for $\tilde{v}_{P}$ and $\tilde{v}_{t}$ are more complicated than before but one can still show that in order for $\tilde{v}_{P} / \rho=\tilde{v}_{t}, t^{*}$ must be equal to $-r$; thus, $t^{*}=0$ is the implementable solution.

Proposition 8 (Land Allocation Trade-OfF). Free provision of parking is an equilibrium even when the mall faces a land allocation trade-off.

Finding the equilibrium value of $P$ is straightforward. We will not spend space to discuss it other than to say that it exists and is unique. Instead, we immediately turn to welfare analysis. As before, welfare is defined as the sum of customers' utility and the mall's profit. The mall's profit is given by Equation (36) and the customers' utility is

$$
U(P, t, s)=\int_{\underline{v}}^{\bar{v}} \max [E(u \mid P, t, s), u(w+r)] d F(v),
$$

where

$$
E(u \mid P, t, s)=\rho(s) u(w+v-P-t)+(1-\rho(s)) u(w-t) .
$$

The welfare maximizer does not have to satisfy the constraint $s=1-F(\tilde{v})$ other than respecting the fact that if $s<1-F(\tilde{v})$, then $P$ will be adjusted to satisfy this constraint, and if $s>1-F(\tilde{v})$, then the firm will treat the share of land devoted to parking as a fixed cost. This means that what we are interested in is $W_{s}$ when $\Pi_{s}=0$. Like before the derivative of the welfare function with respect to $s$ at the profit-maximizing share of land allocated to parking is $U_{s}(P, t, s)$ :

$$
\begin{aligned}
\left.W_{s}\right|_{\Pi_{s}=0} & =U_{s}=\int_{\tilde{v}}^{\bar{v}} E_{s} d F(v) \\
& =\int_{\tilde{v}}^{\bar{v}}\left[\rho^{\prime}(s)(u(w+v-P-t)-u(w-t))\right] d F(v)<0 .
\end{aligned}
$$

This equation says that society wants the parking lot to be smaller. However, this is confounded by the fact that $\partial P / \partial s \leq 0$ and as before $\left.W_{P}\right|_{\Pi_{P}=0}=U_{P}=-\rho(s) \int_{\tilde{v}}^{\bar{v}} u^{\prime}(w+v-P-t) d F(v)<$ 0 . Thus, if society imposes a smaller parking lot, the mall will increase the price of the good and this may decrease welfare. If, however, $\partial P / \partial s$ is sufficiently small, then the welfare gain due to decreased parking lot size outweighs the welfare loss due to the increase in the price of the good. Even if $P$ is set by competitive considerations, it will probably still be that $\partial P / \partial s<0$, because the marginal cost of shopping area is surely higher than the marginal cost of a parking lot. Thus, increasing the parking lot size decreases the marginal cost and thus the price of the good. This gives the key result of this section.

Proposition 9 (Maximum and Minimum Parking Requirements). If the mall faces a binding land allocation trade-off, society wants a smaller parking lot than the shopping mall. However, this may be confounded by the fact that a smaller parking lot results in a higher price. 
This explains the maximum parking requirements that have been imposed by some cities around the world. Notice, however, that these regulations are justified when there is a binding trade-off between land devoted to parking and shopping. If this trade-off is negligible (as in suburban malls) or there is a way to change regulations to remove this trade-off, then we are back in the model of Section 3.

\section{DISCUSSION}

5.1. General Applications. Any model where individuals are risk averse and the outcome is uncertain may benefit from considering this article's basic insight. Essentially, we show that if there is a choice between a priori fees and ex post fees, then the former suppresses demand more than the latter. This could explain why, in general, job candidates do not have to pay an application fee. On the other hand, universities generally do have application fees because they have a large excess demand. Thus, they use an application fee because it is the most effective way to reduce it. This theory may also explain why restaurants rarely have cover charges or special charges for tables with a view. In contrast, again, popular nightclubs have a cover fee specifically to reduce demand.

Sometimes, an ex post fee can be similar to an a priori fee. For example, if customers were not allowed to return goods or were charged for this costly service, this would mean that the payoff when they lost would be decreased, so it would be similar to an a priori fee. In other cases, strategic reactions can change an ex post fee into an a priori fee. For example, if stores charged a fee for using a credit card, then customers would carry more cash-which does have a small opportunity cost. Although this cost may be small, it would still be equivalent to making the customers pay an a priori fee. This may explain why stores embed the cost of credit card fees in the price. Notice that this policy is not without a cost. Customers who pay cash are implicitly paying two fees, one for carrying cash and another for processing the credit card they do not use.

We should also be clear when we think the insight does not apply. If the outcome of the interaction is known-for example, free employer-provided parking-then our insight is mute. Also, if the cost of the service and the discovery of its value happen simultaneously, then this theory is silent. For example, at many Internet sites, such as media platforms and search engines, consumers use the service for free and it is paid for by advertisers. However, the implicit cost of these services is paid at the same time as the discovery of value and our insight is not applicable.

5.2. Search Theory and Parking. Our article takes parking as the cost of a search good. Modern search theory is most active in two literatures, labor and money (Moscarini and Wright, 2010). Like money, transportation is an intermediate good, and, unlike money, it is often motivated by search. Despite these facts, this potentially fruitful methodology has not been exploited. Our model of search is trivial, and yet we are able to explain a puzzling empirical phenomenon.

In our model, search is partially directed (Menzio, 2007) because consumers know some characteristics of the good before searching (the price of the good and the parking fee) but do not know their final valuation. In our base model, search is nonrival (Eeckhout and Kircher, 2010) because the search only fails with a fixed, exogenous probability. When we have a fixed parking lot size, search becomes rival in high demand periods, but since we only have one shopping mall, we do not observe the interesting sorting found in Eeckhout and Kircher (2010). Both of these issues would make it hard to immediately generalize our model to one of imperfect competition. In a model of imperfect competition, partially directed search would be one method of avoiding the Diamond paradox (Diamond, 1971). Another standard method of avoiding the Diamond paradox is assuming that a significant fraction of the population has zero search costs. This is obviously uninteresting in the transportation literature.

In order to maintain tractability, much of the search literature (for example, Burdett and Mortensen, 1998, and Eeckhout and Kircher, 2010) assume risk neutrality. However, we find 
that risk aversion is an important part of the explanation of our phenomenon, and, usually, only in the unemployment insurance literature (Baily, 1978; Chetty, 2006) is this further complication considered. These reasons explain the simplicity of our approach. We want a self-contained model, and studying a full equilibrium with partially directed search and risk aversion is technically demanding.

In the money search literature, it has been discovered that search explains many puzzling phenomena, for example, the existence of money itself (Kiyotaki and Wright, 1993) and other financial intermediaries. In the urban and transportation economics literatures, it clearly has an impact on cruising, the incentive to shop at multiple stores, and overall can have a significant impact on traffic congestion.

Our model may also have an interesting implication for the labor search theory. It suggests that firms, not just the government, may want unemployment insurance. Why is this? Essentially, because it could increase their pool of applicants. Recognize that unemployment insurance is intended for people who are searching for a job, and as recent research by Aguiar et al. (2013) shows, there is a significant choice between working (or searching for work) and other household production. Thus, if one takes the reservation value as the monetary value of household production, unemployment insurance would be equivalent to a negative parking fee. Remember that in the base model, the shopping mall actually wants a negative parking fee to insure the marginal customer. Thus, in this variation, firms may want the government to provide unemployment insurance. In contrast, in Baily (1978; see also Chetty, 2006), unemployment insurance is simply insurance, softening the impact of the stochastic nature of employment. This may not only give a new motive for unemployment insurance but also have different implications about its structure. We know that one implication of our model (no application fees) is a general rule in the labor market. Would employers also embrace unemployment insurance?

5.3. Alternative Hypotheses. We now discuss some alternative hypotheses that could explain free parking. This discussion will relate our article to some nearby literatures and contains some simple logic trying to explain why these literatures have not addressed the problem.

5.3.1. Transaction costs. Perhaps, the simplest alternative explanation for free parking is transaction costs. After all, the average cost of parking is not that large. However, this relies on the standard method of having an employee dedicated to collecting parking fees. A simpler and practically costless solution would be to have every cashier in the mall be able to collect a fixed fee for parking. The customer then receives a token and uses it to exit the parking lot. This would only require vending machine technology, which was invented in the 1880s. Using modern technology, there are many more sophisticated methods available. We would also like to point out that information booths could charge for their services. Why not charge a small fee to tell customers where goods are located? The obvious answer is that stores would object because this discourages search. But then we must ask: If information should be free to encourage search why not parking? At the same time, the fact that shopping malls hire staff for these free information booths and do not pay someone to collect parking fees puts an even heavier strain on the transaction cost hypothesis. If the mall wanted to charge directly for parking, it would.

5.3.2. Two-sided markets. A shopping mall is, in fact, a two-sided market. Shopping malls are platforms, needing to attract both stores and customers. Rochet and Tirole $(2003,2007)$ define a two-sided market as one where the quantity transacted depends not only on the level of fees (the total price charged by the platform) but also on the distribution of fees between the two sides. In such settings, one side of the market usually cross-subsidizes the other side. The existence of cross-group externalities is the defining property of such markets (Armstrong, 2006; Rysman, 2009). In general, the distribution of the total price between the end users obeys the standard Lerner index rules. That is, the price charged to one side is inversely proportional to the elasticity of demand on that side (Rochet and Tirole, 2003, 2007; Armstrong, 2006; Rysman, 
2009). To a first order, our results coincide with the predictions of this theory. In our analysis, the equivalent of supply is marginal cost, which is constant. Thus, the demanders should and do pay the fee. However, this approach would be silent on whether parking should be free or not. It would be a possible equilibrium, but there would be a continuum of equilibria. In contrast with risk aversion and search, there is a unique equilibrium where the cost of parking is embedded in the price. Thus, we expect that analyzing a two-sided market would only result in a stronger incentive to provide free parking with our key elements and without them would be mute.

5.3.3. Price discrimination. There is no paper in this literature that explains free parking. We suspect this is because price discrimination gives the wrong incentives. A shopping mall must choose between a high parking fee and a high price for the good. A high price for the good will suppress the demand of large purchasers - the most profitable customers. A high parking fee only discourages customers who make small purchases. In general, the fixed fee should be set equal to the consumer surplus of the marginal customer; in contrast free parking says the fixed fee is zero. Thus, we believe that this cannot explain the phenomenon.

5.3.4. Imperfect competition. The argument here would be that competition should decrease all fees, so, perhaps, parking is free purely because of competition. However, we expect that the price of the good will be more susceptible to competition than the parking fee. A parking fee is equivalent to a fixed tax for shopping and raising the price is equivalent to a marginal tax. In any textbook analysis, fixed taxes are better. Thus, given two malls charging the same total fee, customers would choose the one with a high fixed fee and a low marginal fee. Although we certainly think that it would be a worthwhile extension of our article to analyze imperfect competition, we do not believe that this alone can explain the phenomenon.

\section{CONCLUDING REMARKS}

We have now taken a first step toward understanding what stores want the price and quantity of parking to be. In the case of the shopping mall-where the parking provider and the store are united-we find that shopping malls want parking to be free. We further find that society also wants parking to be free, and it generally wants the shopping mall to provide more parking. The main message of this article is not that parking fees should be zero but that the cost of parking should be absorbed in the price of the good. It is not that parking fees are bad but that raising the price of the good is better.

Free provision of parking is a robust result. It holds as long as the mall is risk neutral and the customers are risk averse. The results are independent of the degree of risk aversion and the level of the (nondegenerate) probability that the customer cannot find the good he wants at the mall. It holds if the mall provides vouchers, prices in a competitive manner, and even if it has a trade-off between space for shopping and parking. This result may change if there is a significant negative externality from parking and will if enough individuals want to use the mall's parking lot for other purposes (for example, to go to a park, restaurant, etc.). In the latter case, the mall will often want to collect revenue from these individuals. This explains the observation of positive parking fees in urban malls.

This article is one of the first to justify the standard practice of imposing minimum parking requirements on shopping malls. In some popular press and planning circles, minimum parking requirements are deemed to be the worst planning rules. We, on the other hand, neither want to dismiss them altogether nor blindly endorse them for all land uses. Our results are specific to shopping mall parking, and they show that there is a sound basis for minimum parking requirements in this context. However, if there is a binding land allocation trade-off, towns and cities may want to impose maximum instead of minimum parking requirements.

We do not claim that our results apply to all forms of parking, and we believe that towns and cities should avoid one-size-fit-all policies. Different parking fees and requirements must be imposed for different land uses and in urban versus suburban areas. Given the surprising 
robustness of free parking, the natural next question is how society should price parking in urban areas. Does society want the external costs of congestion to be reflected in the price of goods instead of the parking fee? Under what conditions will it want to charge for parking? Could it possibly want to use hourly parking fees to increase business for urban stores despite the potential increase in congestion? How do the results change in the presence of public transportation and modal choice? These questions are left to future research.

\section{SUPPORTING INFORMATION}

Additional Supporting Information may be found in the online version of this article at the publisher's website:

\section{Appendix.}

\section{REFERENCES}

Aguiar, M., E. Hurst, and L. Karabarbounis, "Time Use during the Great Recession," American Economic Review 103 (2013), 1664-96.

Anderson, S., And A. de Palma, "The Economics of Pricing Parking," Journal of Urban Economics 55 (2004), 1-20.

— AND — , "Parking in the City," Papers in Regional Science 86 (2007), 621-32.

Arbatskaya, M., K. Mukhopadhaya, and E. Rasmusen, "The Parking Lot Problem," Working Paper 2007-04, Department of Business Economics and Public Policy, Kelley School of Business, Indiana University, 2007.

Armstrong, M., "Competition in Two-sided Markets," RAND Journal of Economics 37 (2006), 668-91. ARnott, R., "Spatial Competition between Downtown Parking Garages and Downtown Parking Policy," Transport Policy 13 (2006), 458-69.

- A. de Palma, And R. Lindsey, "A Temporal and Spatial Equilibrium Analysis of Commuter Parking," Journal of Public Economics 45 (1991), 301-35.

, AND E. InCI, “An Integrated Model of Downtown Parking and Traffic Congestion," Journal of Urban Economics 60 (2006), 418-42.

— AND - "The Stability of Downtown Parking and Traffic Congestion," Journal of Urban Economics 68 (2010), 260-76.

2013

— , AND J. Rowse, "Modeling Parking," Journal of Urban Economics 45 (1999), 97-124.

, AND —_ "Downtown Parking in Auto City," Regional Science and Urban Economics 39 (2009), $1-14$.

Baily, M. N., "Some Aspects of Optimal Unemployment Insurance," Journal of Public Economics 10 (1978), 379-402.

Barberis, N., M. Huang, and R. Thaler, "Individual Preferences, Monetary Gambles, and Stock Market Participation: A Case of Narrow Framing," American Economic Review 96 (2006), 1069-90.

Burdett, K., And D. Mortensen, "Wage Differentials, Employer Size, and Unemployment," International Economic Review 39 (1998), 257-73.

Calthrop, E., and S. Proost, "Regulating On-Street Parking," Regional Science and Urban Economics 36 (2006), 29-48.

Chetтy, R., "A General Formula for the Optimal Level of Social Insurance," Journal of Public Economics 90 (2006), 1879-901.

Cohen, A., And L. Einav, "Estimating Risk Preferences from Deductible Choice," American Economic Review 97 (2007), 745-88.

Connoly, J., And B. Rogoffg, "Keeping Track of US Mall Visits," International Council of Shopping Centers, Research Review 15 (2008), 5-9.

Cutter, W., And S. Franco, "Do Parking Requirements Significantly Increase the Area Dedicated to Parking? A Test of the Effect of Parking Requirements Values in Los Angeles County," Transportation Research Part A: Policy and Practice 46 (2012), 901-25.

Diamond, P. A., "A Model of Price Adjustment," Journal of Economic Theory 3 (1971), 156-68.

Drewianka, S., "Constrained Labor Supply and Risk-Aversion," Economics Letters 101 (2008), 130-33.

Eeckhout, J., And P. Kircher, "Sorting versus Screening: Search Frictions and Competing Mechanisms," Journal of Economic Theory 145 (2010), 1354-85. 
Glazer, A., and E. Niskanen, "Parking Fees and Congestion," Regional Science and Urban Economics 22 (1992), 123-32.

Harrison, G., and E. Rutstrom, "Risk Aversion in the Laboratory," in J. Cox and G. Harrison, eds., Research in Experimental Economics (Bingley, UK: Emerald Group Publishing Limited, 2008), 41196.

Holt, C., And S. Laury, "Risk Aversion and Incentive Effects," American Economic Review 92 (2002), $1644-55$

International Council of Shopping Centers and Urban Land Institute, Parking Requirements for Shopping Centers: Summary Recommendations and Research Study Report (Washington: Urban Land Institute, 2003).

Jakle, J., AND K. Sculle, Lots of Parking: Land Use in a Car Culture (Charlottesville: University of Virginia Press, 2004).

Kiyotaki, N., And R. Wright, "A Search-Theoretic Approach to Monetary Economics," The American Economic Review 83 (1993), 63-77.

Konishi, H., ANd M. SANDFort, “Anchor Stores,” Journal of Urban Economics 53 (2003), 413-35.

Menzio, G., "A Theory of Partially Directed Search," Journal of Political Economy 115 (2007), 748-69.

Moscarini, G., AND R. Wright, "Introduction to Search Theory and Applications," Journal of Economic Theory 145 (2010), 1319-24.

Rochet, J.-C., ANd J. Tirole, "Platform Competition in Two-Sided Markets," Journal of the European Economic Association 1 (2003), 990-1029.

— AND — - "Two-Sided Markets: A Progress Report," RAND Journal of Economics 37 (2007), 645-67.

Rysman, M., "The Economics of Two-Sided Markets," Journal of Economic Perspectives 23 (2009), 125-43.

Shoup, D., "The Trouble with Minimum Parking Requirements," Transportation Research Part A 33 (1999), 533-74.

- The High Cost of Free Parking (Chicago: American Planning Association, 2005).

- "Cruising for Parking," Transport Policy 13 (2006), 479-86.

U.S. Department of Transportation, 1990 Nationwide Personal Transportation Survey (Washington, DC: U.S. Department of Transportation, 1999).

van Ommeren, J., And D. Wentink, "The (Hidden) Cost of Employer Parking Policies," International Economic Review 53 (2012), 965-78.

,$- \ldots$, and J. Dekkers, "The Real Price of Parking Policy," Journal of Urban Economics 70 (2011), 25-31.

,$- \frac{1}{-}$, AND P. RieTVELd, "Empirical Evidence on Cruising for Parking," Transportation Research Part A: Policy and Practice 46 (2012), 123-30.

- "Congestion Theory and Transport Investment," American Economic Review Papers and Proceedings 59 (1969), 251-60.

Vickrey, W., "The Economizing of Curb Parking Space," Traffic Engineering (1954), 62-67 (Reprinted in Journal of Urban Economics 36 (1994), 42-65).

Wheaton, W. "Percentage Rent in Retail Leasing: The Alignment of Landlord-Tenant Interests," Real Estate Economics 28 (2000), 185-204.

Willson, R., "Local Jurisdiction Parking Requirements: A Survey of Policies and Attitudes," Working Paper, Department of Urban and Regional Planning, California State Polytechnic University, 1996. 